\title{
Market Knowledge, Blue Ocean Strategy, and Competitive Advantage (Direct and Indirect Relationships and Impact)
}

\author{
Abdulraheem Ali Alghamdi \\ College of Administrative and Financial Sciences, Taif University, Saudi Arabia
}

Copyright $(2016$ by authors, all rights reserved. Authors agree that this article remains permanently open access under the terms of the Creative Commons Attribution License 4.0 International License

\begin{abstract}
This study deals with an important and vital subject that focuses on determining the role of market knowledge and Blue Ocean Strategy in achieving competitive advantage, and that is because of the scarcity of management studies in general, and marketing studies in particular, which addressed the nature of the relationship and impact between these three concepts. The study problem was represented by the question: what is the state of the Blue Ocean Strategy in Saudi Arabian organizations, how is it affected by market knowledge and what is its impact on achieving competitive advantage. This study aims to reveal the extent of the realization of the organization under study of market knowledge and Blue Ocean Strategy. It also aims to determine the relationship and impact between market knowledge dimensions and the dimensions of the Blue Ocean Strategy, determining the relationship and impact between the Blue Ocean and the dimensions of the competitive advantage strategy, the relationship and impact between market knowledge dimensions and competitive advantage dimensions and determining the relationship and the indirect impact of market knowledge on achieving competitive advantage through the Blue Ocean Strategy. The study was conducted on employees who occupy supervisory positions in Marketing Department of Saudi Telecom Company. The number of valid questionnaires for analysis amounted to (64), which were analyzed using statistical software (SPSS). The study reached several conclusions, including: There is a high degree of acknowledgement among participants in the study about: market knowledge dimension, Blue Ocean Strategy and competitive advantage; there is a relationship and impact between market knowledge dimension and Blue Ocean Strategy dimension; there is a relationship and impact between Blue Ocean Strategy dimension and competitive advantage dimension; there is a relationship and impact between market knowledge dimension and competitive advantage dimension, there is a relationship and an indirect impact of market knowledge on achieving competitive advantage, and that is through the Blue Ocean Strategy.
\end{abstract}

Keywords Blue Ocean Strategy, Market Knowledge, Competitive Advantage, Saudi Telecom Company (STC)

\section{Introduction}

Knowledge management is considered as one of the modern management concepts that get increasing attention of researchers and of those responsible about businesses management. This comes as a result of the development of the means of science, knowledge and communication and the urgent need for businesses to convert their work into knowledge based activities that provide them with adequate opportunities. For excellence, increased productivity and leadership and increased ownership of intellectual capital [1]. On the other hand, competition has become the feature of our current era, as many organizations were engaged in a bloody conflict (great competition) in the face of decreasing profits in order to obtain market share and to achieve a profitable and steady growth. Now most organizations are looking for strategies to help them in competitive excellence, to obtain a bigger market share and maintain market leadership [2]. For that, organizations tried not to enter in a direct competition to protect their economic entities [3]. The Blue Ocean Strategy is considered a competitive and modern marketing strategy, which led to achieving growth and profit to organizations (through the creation of new demand and by opening space of new markets that are free of conflicts and that had not been contaminated by red (the color of the bloody competition), as well as its readiness for growth). [4] are both considered as the founders of the Blue Ocean Strategy concept, who after fifteen years of research and after analyzing one hundred and fifty comprehensive strategy movements of 30 industries, reached a strategy they called the Blue Ocean Strategy, where they introduced different methods and techniques in how to use the Blue Ocean strategy to create a new demand 
in new markets and to stop efforts aimed at beating competition. They also stated that the Blue Ocean Strategy mainly involves rebuilding the boundaries of the market, and they stressed that companies that use the Blue Ocean Strategy focus on creating new growth and new value by addressing the problems of the product instead of improving the product itself [5].

Blue Ocean Strategy has been used by a number of researchers in a number of countries around the world and was found to be a good strategy for creating a market free of competitive conflicts [6]; [7]; [8]; [9]. [6] compared the Blue Ocean Strategy to other strategies and found that Blue Ocean Strategy has an advantage in determining the market more clearly as compared to other strategies. [8] reported that the Blue Ocean Strategy enable managers to possess a unique value to consumers. [7] proved that the use of the Blue Ocean Strategy enables companies to create more value. While [9] mentioned that the Blue Ocean Strategy forces companies to effect change.

In this research, the researcher examines the relationship between market knowledge and the Blue Ocean Strategy and its impact on the achievement of competitive advantage for organizations in the marketing environment of the Kingdom of Saudi Arabia.

\subsection{Research Problem}

Marketing success requires knowledge of the needs and desires of consumers and working to provide products that satisfy these needs, and thereby improving the mental image the consumer has about the facility and its products, and that requires the analysis of the consumer behavioral patterns of Market participants [10]. On the other hand, knowing competitors enables the business entity to confront them, although competitors try to make their knowledge hard to be imitated, but the behavior products, and services of competitors provide opportunities for business entities to learn from, through the analysis of strengths and weaknesses [11]. Furthermore, research and development and market analysis aim to determine the demand, the nature of competition trends and the knowledge of the prevailing technological changes in the product market and its impact on the change in the needs and desires of consumers, as the integration of market knowledge provides a base of information that enables the administration to choose a strategy to achieve the competitive advantage in the target market [10].

The subject of competitive advantage has attracted the attention of a large number of researchers, mainly because of the fierce and powerful competition that organizations face. The analysis of the literature of strategic thinking showed that many intellectual contributions attempted to explain the sources that allow the organization to achieve the competitive advantage. The Blue Ocean Strategy is perhaps one of the intellectual contributions and modern marketing strategies used by some organizations to pull itself out of the powerful and fierce (bloody) market competition.

And because some organizations suffer from Marketing Myopia phenomenon, which does not enable them to exploit growth opportunities in unexplored markets, they are exposed to threat, delay in growth and eventually leaving the market [12]. Other organizations look deeply for undiscovered markets and are try to reach places in the market that competitors have not reached yet, where these organizations use their own strategies for the blue market.

After reviewing the Literatures, the researcher has noted the following:-

1. There exist studies which addressed the role of market knowledge in the identification and selection of competitive strategies (Blue Ocean Strategy is considered one of the competitive strategies), such as [13] study, study of [10]

2. Some studies focused on the role of the Blue Ocean Strategy in achieving competitive advantage, including [3], [14] study, [15] study, [2] study, and [16] study.

3. Some studies focused on the role of market knowledge in achieving competitive advantage for example, [17] study, [18] study and [19] study.

4. Lack of studies (as per the knowledge of the researcher) that addressed the Blue Ocean Strategy in Saudi Arabia.

5. Lack of Arab and foreign studies (to the best knowledge of the researcher) that studied the role of market knowledge in the adoption of the Blue Ocean Strategy.

6. There is a clear failure of the researchers in studying the intermediary role of the Blue Ocean Strategy on the relationship between market knowledge (as the independent variable) and achieving the competitive advantage (as the dependent variable).

Based on the above, this study is intended to fill this research gap by examining the extent of the application of the Blue Ocean Strategy in organizations in Saudi Arabia, and examining the role of market knowledge in the adoption of the Blue Ocean Strategy and its impact on achieving competitive advantage. It also tries to examine the intermediary role of the Blue Ocean Strategy in the relationship between market knowledge (as the independent variable) and achieving competitive advantage (as the dependent variable).

The problem of this study, therefore, stems from the scarcity of field research in the Arab Environment in general [14] and the Saudi Arabian environment in particular, which deals with market knowledge and its impact on the adoption of the Blue Ocean Strategy and its impact on activating its role and using it to achieve the competitive advantage. This means that the problem of the study is represented by trying to figure out the availability of the requirements and of the elements of the Blue Ocean Strategy the environment of Saudi Arabia, and to see how this strategy is affected by market knowledge, as well as to study the impact of the Blue Ocean Strategy on the competitive advantage. The study 
problem can therefore be embodied in the following major question:

"What is the status of the Blue ocean Strategy in the Saudi organizations, how is it affected by market knowledge and what is its inpact on achieving competitive advantage?"

From the above question, the following questions can be derived:

(A) Does the organization under study have a perception of the Blue Ocean Strategy?

(B) What is the size and nature of the market knowledge that the organization under study has?

(C) Are there a relationship and a statistically significant impact between market knowledge dimensions (knowing customers and knowing competitors) and the Blue Ocean Strategy dimensions (increasing, elimination, creativity and reduction)?

(D) Are there a relationship and a statistically significant impact between the Blue Ocean Strategy dimensions (increasing, elimination, creativity and reduction) and the competitive advantage dimensions (cost, flexibility, innovation, quality and delivery)?

(E) Are there a relationship and a statistically significant impact between market knowledge dimensions (knowing customers and knowing competitors) and competitive advantage dimensions (cost, flexibility, innovation, delivery and quality)?

(F) Are there a relationship and an indirect and statistically significant impact of market knowledge on achieving the competitive advantage through the Blue Ocean Strategy?

\subsection{Research Objectives}

This research seeks to achieve the following objectives:

1. Identify the extent of awareness of staff in the Marketing department in the organization under study of the reality of market knowledge and the philosophy of Blue Ocean.

2. Identify the nature of the relationship and impact between market knowledge dimensions (at the macro level) and the Blue Ocean Strategy dimensions (at the macro level), and between each dimension of market knowledge (at the micro level) and the Blue Ocean Strategy dimensions (at the macro level).

3. Identify the nature of the relationship and impact between the Blue Ocean Strategy dimensions (at the macro level) and competitive advantage dimensions (at the macro level), and between each dimension of the Blue Ocean Strategy (at the micro level) and competitive advantage dimensions (at the macro level).

4. Identify the nature of the relationship and impact between market knowledge dimensions (at the macro level) and competitive advantage dimensions (at the macro level), and between each dimension of market knowledge (at the micro level) and competitive advantage dimensions (at the macro level).

5. Identify the nature of the relationship and the indirect impact of market knowledge on achieving competitive advantage through the Blue Ocean Strategy.

6. Reach a set of conclusions and recommendations that could be of benefit both to researchers interested in the subject of study or for practitioners and theoreticians in various business organizations.

\subsection{Research Importance}

This research derives its significance from the importance of the telecommunications sector in the Kingdom of Saudi Arabia as it is a vital and promising sector that has great importance in strengthening the national income of the kingdom [20]. Moreover, the importance of this research can also be captured in two main areas:-

First: the scientific importance and it includes the following:

1. Contributing directly to the definition of the features and nature of the relationship between market knowledge and the Blue Ocean Strategy as a contemporary strategy and the impact of this on competitive advantage as one of the indicators by which to judge the success or failure of the organization.

2. After reviewing previous studies, it was found that there has been a lack of attention among the researchers in the Arab world in general and in Saudi Arabia in particular in studying the relationship between market knowledge and the Blue Ocean Strategy and its impact on the achievement of competitive advantage for organizations. Therefore, this study is intended to contribute to filling this gap. And, "to the best knowledge of the researcher", this study may be the first of its kind in Saudi Arabia, which deals with market knowledge and its impact on the Blue Ocean Strategy and impact of this on the achievement of competitive advantage for organizations.

3. Enriching the Arabic library with field studies related to market knowledge and its impact on the Blue Ocean Strategy and its impact on the achievement of the competitive advantage in organizations.

4. Opening the doors to new studies related to the concept of market knowledge, the Blue Ocean strategy and competitive advantage.

Second: the applied importance and it includes the following:

1. Highlighting the Blue Ocean philosophy as a new approach that enables organizations that adopt it to face the challenges and to keep up with developments and environmental change in all its complexity, in order to achieve competitive excellence [14].

2. The importance of the research is also derived from its 
ability to offer businesses a tool for the creation of new competitive areas in which other entities cannot compete with them, at least in the short term. It also encourages managers to adopt creative thinking on an ongoing basis to ensure excellence and to put competitors out of the game. Moreover, it encourages businesses to continue to innovate and find new markets so that they can control the demand and create new demand.

\section{Literature Review and Research Hypotheses}

This part covers previous studies and publications that have discussed the theory, the methodology and the practical aspects of the subject. Combining blue ocean strategy, market knowledge and competitive advantage is a fairly new subject. However, in this part, we are going to survey both Arabic and foreign publications which tackled the subject.

\subsection{Market Knowledge}

[21] defined market knowledge as "a set of marketing data and information obtained from market, and it represents the vital part of the company knowledge about realizing the importance of this market".

Market knowledge requires studying three main components [1]; [13], namely:

\section{A. Knowing the Customers}

The client is the main focus of all marketing activities, because the business organizations ability to compete in the market depends on the amount of satisfaction that can be provided to the client. [10] has pointed out that successful marketing requires directing all efforts to identify the needs and desires of consumers and making an effort to provide products that the consumer need, and thereby improving the mental image he has about the organization and its products. This requires analyzing the behavioral patterns of consumers in the given market members.

\section{B. Knowing the Competitors}

[22] has defined competitor as "any business organization or individual involved in getting a share of the money customers spend on the same products." [23] defines competitors as other business organization that offer the same products or substitutes for the market.

\section{Market Research}

Marketing research is defined as "the function associated with consumers and with the public buyers through information, that is used to identify and clarify the opportunities and threats to generate, refine and evaluate the marketing activity, monitor the performance and develop and understand marketing as a series of operations" [24].

\subsection{Blue Ocean Strategy}

The term Blue Ocean Strategy is considered as one of the modern terminologies in the field of business administration in general and marketing management in particular. [4] are considered to be the first to use this term. It refers to the clear blue water color that is not contaminated or infected by the bloody red color of water [14]. [5] defined Blue Ocean Strategy as Unused space in the market, where demand can be created, with a chance for profitable growth.

Dimensions of Blue Ocean Strategy include (increasing, elimination, reduction, and creativity).

\section{Increasing}

Increasing means that the organization is adding some activities, procedures or materials that result in increased and improved quality of the products offered to customers, and that lead to an increased level of the profits size.

\section{Elimination}

Elimination means that the organization excludes any unnecessary processes to reduce costs without affecting the quality, sales and profits, such as the exclusion of individuals who disturb the organization's work and who get high wages [2].

\section{Reduction}

Reduction means that the organization cuts or reduces some of the work processes that it deems unnecessary or unjustified and that can contribute to reducing the overall costs with maintaining the stability of profits and increasing the quality, like reducing some unnecessary services provided to customers [4].

\section{Creativity}

Creativity means that the organization is creating new jobs and products and is also creating a better working environment for its employees. In addition, its use of innovative ways and methods in the marketing processes (creation of a product, creation of a price, creation of promotion, creation of distribution) [2].

\subsection{Competitive Advantage}

Competitive advantage is defined as the It is the Organization's ability to perform its tasks in a way that is difficult for its competitors to imitate. Authors have disagreed on the number of dimensions. Some of them focused on two dimensions and some of them focused on more than that reaching five dimensions. It is noticeable dimensions of advantage dimensions addressed by the researchers are confined to (cost, quality, flexibility, delivery and innovation). In this study, we will use these dimensions. 


\section{Cost}

Cost is one of the most basic dimensions for competition and that many organizations tried to rely on reducing their product cost to achieve competitive advantage, which means that the organization carry on the production and marketing of products at the lowest possible cost compared to its competitors, enabling it to sell at a lower price [25], thereby increasing market share [26].

\section{Quality}

Quality is a critical factor for the success of many organizations; industrial or service, public or private, as it is a main pillar to achieve the competitive advantage [25].

\section{Flexibility}

[27] defines flexibility as the ability to change from one product to another and from one customer to another with minimal possible cost or impact.

\section{Delivery (Speed)}

The delivery or time dimension is considered as the basic rule of competition between companies in the market by focusing on reducing the time and increasing the speed of the design of new products and presenting them to customers in the shortest possible time [28].

\section{Innovation}

[29] sees that innovation is the introduction of new products and processes through the development of work and techniques used.

\subsection{The Relationship between Market Knowledge and Blue Ocean Strategy}

Despite the lack of studies on market knowledge and its role in the adoption of the Blue Ocean Strategy according to the knowledge of the researcher), some studies are found to have discussed the role of market knowledge in the identification and selection of competitive strategies (Blue Ocean Strategy is considered as one of the competitive strategies), including [13], which aimed to clarify the role of market knowledge in the selection of competitive strategies in seven Jordanian private universities and to explain the extent of achieving competitive advantages resulting from the choice of students who study in those universities where two samples of individuals were taken, the first consisted of (150) administrative employees, and the second sample consisted of(450) students of the Faculty of Business of those universities. One of the most important results of this study is that market knowledge (students, competitors) has a large role in determining the competitive strategic choice. Moreover, [10] aimed to determine the impact of market knowledge on the selection of competitive marketing strategies and performance excellence in the durable goods market sector. This study has reached conclusions that managers in the companies under study are aware of the importance of knowledge of factors affecting the market, and that they care about the needs of consumers and competitors more than they care about research and development.

Based on previous studies the following hypothesis has been formulated:

The first hypothesis: That there is a relationship and statistically significant impact between market knowledge dimensions and the Blue Ocean Strategy dimensions (at the macro level), and between each dimension of market knowledge (at the micro level) and the Blue Ocean Strategy dimensions (at the macro level).

\subsection{The Relationship between Market Knowledge and Competitive Advantage}

Regarding the relationship between the market knowledge and competitive advantage, [16] found that market knowledge leads to the achievement of a significant competitive advantage for organizations. [30]'s study aimed to explore the role of knowledge management in achieving competitive advantage in insurance companies in Nablus city of, from the standpoint of their employees. This study has concluded that there is a role of knowledge in achieving competitive advantage in insurance companies. Furthermore, [17] found that there is a relationship between market knowledge and competitive advantage. [31] also found that the dissemination of knowledge is critical for the success of any organization; as it allows members of the organization to exchange knowledge. Moreover, [19] found that the dissemination of market knowledge enables the achievement of a number of advantages; including the organization achievement of competitive advantage.

Based on previous studies the following hypothesis has been formulated:

The second hypothesis: That there is a relationship and a statistically significant impact between market knowledge dimensions and competitive advantage dimensions (at the macro level), and between each dimension of market knowledge (at the micro level) and competitive advantage dimensions (at the macro level).

\subsection{The Relationship between Blue Ocean Strategy and Competitive Advantage}

Regarding the role of the Blue Ocean Strategy in creating competitive advantage, some studies were found relevant. Those include [32], which aimed to find out the dimensions of the role of the Blue Ocean Strategy (reduction, exclusion, increase and innovation) in achieving a competitive advantage. The results showed that respondents of the sample believe that Telecom Company in Algeria adopts the dimensions of Blue Ocean Strategy, particularly the increase and innovation dimension. Furthermore, [33] found that the company (IMAX) has used the Blue Ocean Strategy to move from educational films market (mostly) to the 
animation market, and ultimately to feature film market and thus the transition from small-revenue market to a more financially stable market. In [5] study, the Blue Ocean Strategy was applied to an industrial Jordanian firm owned by the private sector. The main results of this study indicate that the company was able to identify a number of new products that could lead to the development of new markets, particularly (Blue Ocean markets). Moreover, [33] found that the IKEA Company in Nanjing, China, has applied the Blue Ocean Strategy successfully and that it is supported by the value of good innovation for both consumers and the company. It is a good example of the successful implementation of a global blue ocean strategy.

[17] has also conducted a study entitled "Blue Ocean Strategy: A strategic study to help organizations to retain their competitive advantage", where he tried to shed light on the obstacles and constraints facing the application of that strategy like simulation and imitation. The study has compared the competitive environment (Red Ocean Strategy) to the Blue Ocean Strategy, and looked at the importance of the role of management in the use of Blue Ocean Strategy to increase revenues. It also showed the importance of innovation and its value in the application of this strategy, and in helping organizations to stay in the competitive market. It demonstrated the concept of the first and the second imitator as a crucial issue when considering this strategy and its mechanism of action in the market. [34]'s study was designed to confirm the assumption that the Blue Ocean Strategy is applicable in the (marketing among organizations) (B2B). The study was applied to two business sectors namely: suppliers of chemical building materials and manufacturers of technical equipment. Researchers have concluded that Blue Ocean Strategy is viable and has been successfully applied in the (marketing among organizations) (B2B). This confirms the results of the study conducted by [35] where he noted that the Blue Ocean Strategy is not only applied to goods environment only, but also to business or marketing environment from one organization to another.

[3]'s study aimed to test the relationship between the Blue Ocean Strategy dimensions (follow-up of alternative and alike organizations, going through strategic blocs of organizations, redefining the target consumer group, follow-up of complementary products and services, reconsidering functional and emotional trend of the organizations, the perspective of time) and marketing performance, and that is through the application to the public Company for the Manufacturing of Medicines and Medical Supplies in Jordan. The study found that Blue Ocean Strategy dimensions are used in the company under study without having a prior opinion about such a strategy, and therefore its impacts were not reflected on the performance of the company under study. [14] study aimed to determine the relationship and impact between the Blue Ocean philosophy dimension (increase, exclusion, innovation and reduction) and competitive excellence indicators (cost, flexibility, innovation, delivery and quality), through a survey of a sample of Zain Telecommunication employees composed of (30) individuals. The study found a set of conclusions, most importantly that there is a relationship and impact between the Blue Ocean Strategy and the competitive excellence. [15] study aimed to determine the correlation and impact between the indicators of the Blue Ocean Strategy and the dimensions of the sustainable competitive advantage through the application to (100) branches, units and sections of Zain and Asia Cell Telecom managers. The study found a relationship and a statistically significant correlation between the two key variables. [2] conducted a study aimed to investigate the role of the Blue Ocean Strategy indicators (blue market matrix) (increase, exclusion, innovation and reduction) in achieving competitive excellence (cost, flexibility, innovation, quality and delivery) through the application to the Pepsi factory Kufa. The study found that Blue Ocean Strategy has an important role in achieving prominent and competitive excellence of the company under study.

[36] also studied the extent of the application of Blue Ocean Strategy as well as the Porter theory in the competition for third-generation communications industry $(3 \mathrm{G})$ in China, and that is through surveying consumers opinions about third-generation services. The researchers believe that third-generation operators in China must provide Internet service via mobile phone due to the lack of competition in this market. [8]'s study introduced an application of the Blue Ocean Strategy in the toy industry through value creation to find its impact on the industry. [37] also provided an application of the Blue Ocean Strategy to develop new products, and she reached a strategic approach that can be applied to product development. [38] also introduced an experimental study on five managers in the United Arab Emirates for the Blue Ocean Strategy and how that enables small and large companies (based on their abilities) to open a new undisputed space in the market, and to focus on non-customers instead of the current customers as well as to focus on what the existing customers have in common. [39]'s study focused on logistics service providers (PL3) in South Korea and how they can be leading in this modern industry, using the framework of the Blue Ocean Strategy.

Based on previous studies the following hypothesis has been formulated:

The third hypothesis: there is a relationship and a statistically significant impact between the Blue Ocean Strategy dimensions and competitive advantage dimensions (at the macro level), and between each dimension of the Blue Ocean Strategy (at the micro level) and competitive advantage dimensions (at the macro level).

\subsection{Relationship and the Indirect Impact of Market Knowledge on Achieving Competitive Advantage through the Blue Ocean Strategy}


According to the researcher there are no previous studies that examined the impact of the mediator Blue Ocean strategy in the relationship between the market of knowledge and the competitive advantage, and to achieve the objectives of this study the following hypothesis has been formulated.

The fourth hypothesis: There is an indirect impact that has a statistical significance of market knowledge on achieving competitive advantage through the Blue Ocean Strategy.

\section{Hypothetical Diagram of the Research}

In this research, and based on previous studies and literature review on the research subject, the researcher tried to develop hypothetical diagram within the framework of three key variables, namely:
The first variable: This is represented by market knowledge as an independent variable and it includes two sub-variables (knowing the customers and knowing the competitors).

The intermediate variable: This is represented by The Blue Ocean Strategy with its various dimensions (increasing, elimination, creativity and reduction).

The third variable: represented by competitive advantage, which is the dependent variable, and includes five sub-variables (cost, flexibility, innovation, delivery and quality). The following figure shows the hypothetical diagram of the research, its independent variables, dependent variables and the presumed relations between them.

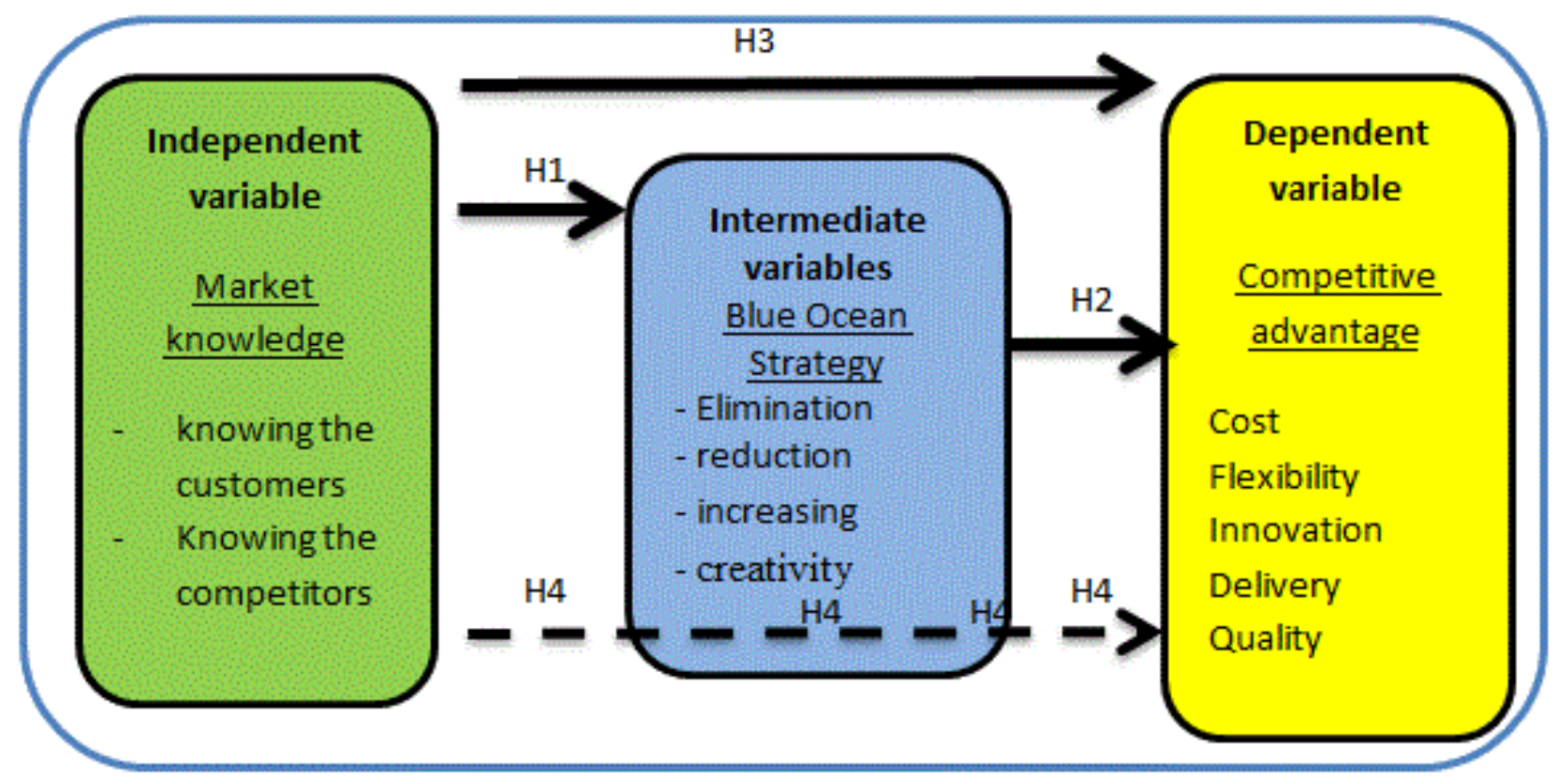

Figure 1. Hypothetical diagram of the research 


\section{Research Design and Methodology}

This part discusses the scientific methodology used in the research, and explains the population and sample used, it tackles the research tool used to verity the validity of the result, and the statistical methods adapted to the information collected.

Depending on the nature of research and information to be obtained to identify the impact of market knowledge on the Blue Ocean Strategy and thus achieving competitive advantage in the Saudi organizations, the researcher, has used the analytical descriptive method that depends on studying the phenomenon in question, and focuses on describing it accurately, and both qualitatively and quantitatively. The qualitative expression describes the phenomenon and illustrates its characteristics, and the quantitative expression gives a numerical description that represents the size of this phenomenon and the degrees of its association with other phenomena [40].

The researcher has relied on two sources of data, namely:

1. Secondary sources by relying on the books and relevant Arabic and foreign previous studies, to consolidate the theoretical framework and to build hypotheses.

2. Primary sources where the researcher used a questionnaire designed by the researcher to serve the objectives of the study. The questionnaire was distributed to the employees who occupy supervisory positions in the Marketing Department in Saudi Telecom Company (STC).

\section{1. The Study Tool}

Due to the nature of the research in terms of objectives, approach and population, preliminary data for this study was collected by the questionnaire, which is considered as one of the most common and widely used research tools in the field of humanities. The researcher has adopted previous studies in its preparation [14]; [3]; [13]; [15]; [2] and [10], which was divided into three parts:

Part I: demographic variable (career level, length of service, educational qualification and age).

Part II: the independent variable "market knowledge" which includes: (1. knowing the customers dimension. 2. Knowing the competitors dimension) and they have been measured using four phrases.

Part III: the intermediate variable (Blue Ocean Strategy) which: (1. the elimination dimension. 2. The reduction dimension. 3. The increasing dimension. 4 . the creativity dimension) and they have been measured using five phrases.

Part IV: the dependent variable "competitive advantage dimensions" which includes: (1. the cost dimension. 2. The quality dimension. 3. The flexibility dimension. 4 The delivery dimension. 5. The innovation dimension), and they have been measured using five phrases.

All statements were formulated on the five points Likert scale as shown below:

\begin{tabular}{|c|c|c|c|c|c|}
\hline Response & $\begin{array}{c}\text { Strongly } \\
\text { agree }\end{array}$ & Agree & Neutral & Disagree & $\begin{array}{c}\text { Strongly } \\
\text { Disagree }\end{array}$ \\
\hline Score & 5 & 4 & 3 & 2 & 1 \\
\hline
\end{tabular}

\subsubsection{Validity of the Questionnaire}

Validity of the Questionnaire means that the questionnaire measured what it was designed for. To verify the Validity of the questionnaire, the questionnaire was presented to a group of faculty members in the Marketing Department and the Business Administration Department at the Faculty of Administrative and Financial Sciences at Taif University who have specialty and experience in this area, in order to express their views and notes related to the appropriateness of the statements to measure what they are developed for, the clarity of the statements, the suitability of each statement to the part to which it belongs and the adequacy of phrases to cover every part of the main research variables, in addition to suggesting what they deem necessary to modify the formulation of statements, delete them or add new phrases to the research tool. Based on the views of the arbitrators, some paragraphs have been deleted; other paragraphs have been modified in terms of language formulation and some statements have been added to the research tool.

\subsubsection{Reliability of the Questionnaire}

Reliability of the Questionnaire means that it will give the same result if it is re-distributed more than once under the same circumstances and conditions, or in other words, it means consistency of the results of the questionnaire and that they do NOT change significantly if re-distributed to sample individuals several times during certain time periods. To test the reliability of the used tool (the questionnaire), alpha Cronbach consistency coefficient (Alpha) and self-credibility tool were used to judge the quality of the survey and its appropriateness to achieve the goal it was used for. The results are shown in Table (1).

It is noted from Table (1) that the reliability values are acceptable for all questions. The survey list included three main focus axes represented by the five points Likert form and consisted of more than one dimension, and each dimension consisted of more than one item. The value of consistency coefficient ranged from $(0.762)$ for the third dimension "the increase" as one of the dimensions of the second axis "the Blue Ocean Strategy" and (0.925) for the fifth dimension "the innovation" as one of the dimensions of the third axis "competitive advantage". Those values are higher than the generally accepted statistical values $(0.70)$ [41].

Table (1) indicates that the values of the credibility factor (the square root of the values of the consistency coefficient), range from (0.814) for the third dimension "the increase" as one of the dimensions of the second axis "the Blue Ocean Strategy" and (0.962) for the fifth dimension "the innovation" as one of the dimensions of the third axis "competitive advantage". 
Table 1. Reliability and credibility coefficients of the survey form

\begin{tabular}{|c|c|c|c|}
\hline Questionnaire parts & Dimensions & Reliability & Credibility coefficient \\
\hline \multirow{2}{*}{ Part I: market knowledge } & Knowing the customers dimension & 0.908 & 0.941 \\
\hline & Knowing the competitors dimension & 0.885 & 0.949 \\
\hline \multicolumn{2}{|c|}{ All statements of market knowledge } & 0.908 & 0.953 \\
\hline \multirow{4}{*}{ Part II: the Blue Ocean Strategy } & Elimination dimension & 0.878 & 0.937 \\
\hline & Reduction dimension & 0.707 & 0.841 \\
\hline & Increasing dimension & 0.762 & 0.814 \\
\hline & creativity dimension & 0.763 & 0.816 \\
\hline \multicolumn{2}{|c|}{ All statements of the Blue Ocean Strategy } & 0.778 & 0.882 \\
\hline \multirow{5}{*}{ Part III: Competitive advantage } & Cost dimension & 0.780 & 0.883 \\
\hline & Quality dimension & 0.851 & 0.922 \\
\hline & Flexibility dimension & 0.817 & 0.904 \\
\hline & Delivery dimension & 0.744 & 0.863 \\
\hline & Innovation dimension & 0.925 & 0.962 \\
\hline \multicolumn{2}{|c|}{ All statements on competitive advantage } & 0.780 & 0.883 \\
\hline \multicolumn{2}{|c|}{ All statements of the questionnaire } & 0.922 & 0.947 \\
\hline
\end{tabular}

Therefore, it could safety be claimed that these coefficients are good enough to achieve the objective of the research and can be relied upon to mainstream the outputs on the whole population.

\subsection{Study Population and Sample}

The number of employees working in the Marketing Department at the Saudi Telecom Company (STC) equals 1535. Due to the fact that this study requires accurate evidence, the study population was represented by employees who occupy supervisory positions in the Marketing Management at STC (manager, deputy manager, assistant manager, head of department, deputy head of department ......... etc.) because they are closer to the understanding of the objectives of this study and therefore understand the questionnaire questions and answer them objectively. The size of the study population equals (71 respondents). Due to the small size of the study population, the researcher has used the comprehensive inventory style, and after collecting the questionnaires, the number of valid questionnaires for analysis was 64 , with a response rate of $90 \%$.

\subsection{Statistical Analysis Methods}

The researcher has used the statistical software (SPSS) to analyze the data. A number of statistical methods were relied upon in the analysis of data, including:

1. Arithmetic mean and standard deviation to describe variables of the study.

2. Consistency coefficient (Cronbach's Alpha) to determine the consistency of the paragraphs of the questionnaire.

3. Pearson correlation coefficient to measure the degree of correlation between the variables of the study.

4. Simple and gradual regression to determine the relationship between independent variables and dependent variables and to determine the variance ratio that can be explained in the dependent variable by the independent variables.

5. Structure Analysis (path analysis) to test the direct and indirect relationships between the dimensions of internal marketing as the independent variable and satisfaction as the dependent variable through the quality service as an intermediate variable to indicate the role of the intermediary in these relations, so as to test the validity of the fourth assumption.

\section{Saudi Telecom Company}

Saudi Telecom Company, known as (STC), is the first operator of telecommunications services in Saudi Arabia. The company was founded under the Council of Ministers Resolution No. 171 dated September $9^{\text {th }}, 2002$ and the Royal Decree No. M 35/ dated April 21 ${ }^{\text {st }}, 1998$ as a Saudi Riyadh-based Joint Stock, and affiliate companies include Kuwaiti Telecommunications Company, and Access whose staff number is equal to 21190 . STC operates through five 
business units: the phone unit, which includes land lines services, phone cards, general lines, pre-paid cards services and business services sector; Mobile Unit, and provides a range of mobile services, including the family mobile, Sawa, messaging services, business services and data and roaming services; Saudi Net Unit, and provides Internet services; STC Services unit to pay electronic bills online; and the Saudi Data Unit for data service solutions. In 2003, the company made available $30 \%$ of its shares on the Saudi bourse in the largest offering ever known in Arab markets. $20 \%$ of the offered shares were allocated for Saudi nationals in their personal capacities, $5 \%$ were allocated for the General Organization for Social Insurance and 5\% for the Public Pension Agency. In 2004 the company lost its monopoly of mobile phone services after the assignment of a second license to Etihad Etisalat. In April 2007 its monopoly of fixed telephone services has ended after a coalition led by Bahrain's Bate cow on a second license offered by the government.

The company adopted an ambitious program that aims to transform government business to follow commercial fundamentals, where the company developed clear strategies that focus on internal restructuring, rehabilitation and development of its staff, reviewing and improving its internal procedures and studying the requirements and needs of its customers, with the need to continue to carry out the duties of the company's national and social responsibilities. The "STC" is considered the leading national company in providing integrated communication services in Saudi Arabia, where the company works continuously to respond to market demands, and keep up with developments and technical improvements in the field of communications and meet the needs of their customers, bearing in mind that this is the way through which the company can establish its position and identity, especially in a changing world in which the role of communications and communication services is growing.

\section{Statistical Analysis of Data}

After encoding and entering data, the statistical program (SPSSv22) was used for conducting statistical analysis of the data obtained from the field study as follows:

First, study sample characterization

Second, descriptive statistics of the study variables

Third, hypotheses testing and analysis of result

Here under, the researcher addresses each element of the previous elements in some detail as follows:

\subsection{Study Sample Characterization}

Table 2 presents the data that determine the qualities and characteristics of the 64 participants in the study.

It is noted from Table (2) that $63 \%$ of study participants occupy the post of Head and Deputy Head of Marketing management in Saudi Telecom Co., 92\% of them have worked in the company for more than five years, $78 \%$ of them have university degrees and $77 \%$ of them aged more than 35 years.

Table 2. Demographic characteristics of study participants

\begin{tabular}{|c|c|c|c|}
\hline & Description & No. & Percentage \\
\hline \multirow{4}{*}{ Career level } & Manager & 10 & $15 \%$ \\
\hline & Assistant Manager & 14 & $22 \%$ \\
\hline & Head of Department & 21 & $33 \%$ \\
\hline & Deputy Head of Department & 19 & $30 \%$ \\
\hline \multicolumn{2}{|r|}{ Total } & 64 & $100 \%$ \\
\hline \multirow{3}{*}{ Work service } & $1-4$ years & 5 & $7 \%$ \\
\hline & $5-9$ years & 26 & $41 \%$ \\
\hline & 10 years and more & 33 & $51 \%$ \\
\hline \multicolumn{2}{|r|}{ Total } & 64 & $100 \%$ \\
\hline \multirow{3}{*}{$\begin{array}{l}\text { Educational } \\
\text { qualification }\end{array}$} & High school or less & 2 & $3 \%$ \\
\hline & University degree & 50 & $78 \%$ \\
\hline & Post- university degrees & 11 & $19 \%$ \\
\hline \multicolumn{2}{|r|}{ Total } & 64 & $100 \%$ \\
\hline \multirow{3}{*}{ Age } & $30-34$ years & 15 & $23 \%$ \\
\hline & 35 to 39 years & 21 & $33 \%$ \\
\hline & 40 years or more & 28 & $44 \%$ \\
\hline \multicolumn{2}{|r|}{ Total } & 64 & $100 \%$ \\
\hline
\end{tabular}

\subsection{Descriptive Statistics for the Study Variables}

The five points Likert scale was used and there relative importance of the variables of the study was identified based on the following equation:

category length $=\frac{\text { variable max.limit }- \text { variable min. level }}{\text { no. of levels }}=\frac{5-1}{3}=1.33$

Therefore, the relative importance will be low if the arithmetic mean value ranges from 1 to 2.33 , moderate if the arithmetic mean value ranges from 2.34 to 3.66 and high if the arithmetic mean value is higher than 3.67. Table (6) displays descriptive statistics for study variables, from the views of the participants in the study. The table shows the high average of the views of the participants in the study about most of the variables of the study, where the arithmetic mean value of the views is close to (4). In other words, most of the views range from "neutral" and "agree" and tend to be "agree".

The average of the views of the study participants about the "dimensions of market knowledge" is (3.81) and the standard deviation is (0.56) which shows that most of the views range from "without opinion" and "agree" and tend to be "agree", and the relative importance of this variable is 
high, where the arithmetic mean value is higher than 3.67. The average of the views of the participants in the study about "the dimensions of the Blue Ocean Strategy" is (3.83) and the standard deviation is $(0.34)$ which shows that most of the views range from "without opinion" and "agree" and tend to be "agree", and the relative importance of this variable is high, where the arithmetic mean value is higher than 3.67. The average of the views of the study participants about the "dimensions of competitive advantage" is (3.81) and the standard deviation is $(0.40)$ which shows that most views range from "without opinion" and "agree" and tend to be "agree", and the relative importance of this variable is high, where the arithmetic mean value is higher than 3.67.

With regard to the variables of market knowledge, it is noted that knowing the customers dimension was at the forefront of market knowledge variables with a mean of 3.94 and a standard deviation of 0.63 , followed by knowing the competitors dimension with a mean of 3.67 and a standard deviation of 0.640 . With regard to the variables of the Blue Ocean Strategy, it is noted that the increase dimension was at the forefront of the Blue Ocean Strategy variables with a mean of 3.93 and a standard deviation of 0.50 , followed by the innovation dimension with a mean of $3.91=$ and a standard deviation of 0.410 , followed by the exclusion dimension then the reduction dimension. With regard to competitive advantage variables, it is noted that the quality dimension was at the forefront of competitive advantage variables with a mean of 3.93 and a standard deviation of 0.570 , followed by the delivery dimension with a mean of 3.91 and a standard deviation of 0.470 , followed by the innovation dimension, then the cost dimension and finally the flexibility dimension.

Table 3. Descriptive statistics for the study variables

\begin{tabular}{|c|c|c|c|c|c|}
\hline Axis & Description & Arithmetic mean & Standard deviation & $\begin{array}{l}\text { The importance order of } \\
\text { the dimension }\end{array}$ & Importance level \\
\hline First & Marketing knowledge & 3.81 & .56 & & High \\
\hline 1 & Knowing the customers & 3.94 & .63 & 1 & High \\
\hline 2 & Knowing the competitors & 3.67 & .64 & 2 & High \\
\hline Second & Blue Ocean Strategy & 3.83 & .34 & & High \\
\hline 1 & Eliminatin & 3.81 & .46 & 3 & High \\
\hline 2 & Reduction & 3.76 & .48 & 4 & High \\
\hline 3 & Increasing & 3.93 & .50 & 1 & High \\
\hline 4 & Creativity & 3.91 & .41 & 2 & High \\
\hline Third & Cometitive Advantage & 3.81 & .40 & & High \\
\hline 1 & Cost & 3.70 & .51 & 4 & High \\
\hline 2 & Quality & 3.93 & .57 & 1 & High \\
\hline 3 & Flexibility & 3.68 & .48 & 5 & High \\
\hline 4 & Delivery & 3.91 & .47 & 2 & High \\
\hline 5 & Innovation & 3.80 & .56 & 3 & High \\
\hline
\end{tabular}




\subsection{Hypotheses Testing and Analysis Results}

The first hypothesis:

"There is a relationship and statistically significant impact between market knowledge dimensions and the Blue Ocean Strategy dimensions (at the macro level), and between each dimension of market knowledge dimensions (at the micro level) and the Blue Ocean Strategy dimensions (at the macro level)."

To test this hypothesis, we used Pearson correlation coefficient between market knowledge and its dimensions and the Blue Ocean strategy and its dimensions and gradual regression as follows:

\section{Correlation Coefficients}

Table (4) displays correlation coefficients between market knowledge and its dimensions and the Blue Ocean Strategy and its dimensions. The table shows high correlation coefficient between the overall average of the study participants' views about market knowledge and the Blue Ocean Strategy as a whole where the value of the correlation coefficient is $(0.763)$. This means that there is a strong proportional (positive) correlation between market knowledge and the Blue Ocean Strategy as a whole, which is significant at the $1 \%$ significance level. There is a strong proportional correlation between the total score of the Blue Ocean Strategy and knowing the competitors where the correlation coefficient value is $(0.705)$, i.e., there is a strong proportional (positive) correlation between the Blue Ocean Strategy as a whole and knowing the competitors, which is significant at the $1 \%$ significance level. There is also a strong proportional correlation between the total score of the Blue Ocean Strategy and knowing the customers where the correlation coefficient value is $(0.660$, i.e. there is a strong proportional correlation between the Blue Ocean Strategy as a whole and knowing the customers, which is significant at the $1 \%$ significance level.

With regard to the relationship between market knowledge dimensions and the Blue Ocean Strategy dimensions (at the micro level) it is noted from Table (4) that there is a strong proportional (positive) correlation between knowing the customers dimension as one of market knowledge dimensions, and the increase dimension as one of the Blue Ocean Strategy dimensions, where the correlation coefficient value is $(0.635)$, which is significant at the $1 \%$ significance level. The lowest value of the correlation coefficient was between knowing the customers market dimension as one of market knowledge dimensions and the exclusion dimension as one of the Blue Ocean Strategy dimensions where the value of the correlation coefficient is $(0.341)$, i.e. there is a weak proportional correlation between the two dimensions and it is significant at the $1 \%$ significance level.

Table 4. Correlation coefficients between market knowledge dimensions and the Blue Ocean strategy dimensions

\begin{tabular}{|c|c|c|c|}
\hline & $\begin{array}{c}\text { Market } \\
\text { knowledge as } \\
\text { a whole }\end{array}$ & $\begin{array}{c}\text { Knowing the } \\
\text { customers }\end{array}$ & $\begin{array}{c}\text { Knowing the } \\
\text { competitors }\end{array}$ \\
\hline $\begin{array}{c}\text { Blue Ocean Strategy } \\
\text { as a whole }\end{array}$ & $.763^{* *}$ & $.660^{* *}$ & $.705^{* *}$ \\
\hline Eliminatin dimension & $.493^{* *}$ & $.341^{* *}$ & $.536^{* *}$ \\
\hline Reduction dimension & $.537^{* *}$ & $.464^{* *}$ & $.496^{* *}$ \\
\hline Increasing Dimension & $.686^{* *}$ & $.635^{* *}$ & $.595^{* *}$ \\
\hline Creativity Dimension & $.593^{* *}$ & $.547^{* *}$ & $.514^{* *}$ \\
\hline
\end{tabular}

** Significant coefficients at the significance level of $1 \%$

\section{Partial Regression}

Table (5) displays partial regression model estimates for the dependent variable (Blue Ocean Strategy as a whole) on the independent variables (market knowledge dimensions). The table clearly shows the significance of the estimated regression model at the significance level of 0.01 as the calculated $(\mathrm{F})$ test value is (183.263) and Sig (P-value $=$ $0.000)$ lower than the level of significance. The table clearly shows the significance of partial regression coefficients (path coefficients) (knowing the customers and knowing the competitors) and the constant value through the $t$ value and Sig (P- value). Market knowledge dimensions that affect the Blue Ocean Strategy as a whole according to the standard partial regression coefficient in the model are:

- Knowing the competitors

- Knowing the customers

The value of the coefficient of determination is (0.584) which shows that market knowledge dimensions as independent variables explain $58.4 \%$ of the changes in the dependent variable (the Blue Ocean Strategy as a whole). Table (5) clearly shows that all partial regression coefficients are positive, indicating a proportional relationship between independent variables (market knowledge dimensions) and the dependent variable (the Blue Ocean Strategy as a whole). 
Table 5. Partial regression model estimates

\begin{tabular}{|c|c|c|c|c|c|c|}
\hline \multirow{2}{*}{ Independent variables } & \multicolumn{5}{|c|}{ estimates } & \multirow{2}{*}{ Order } \\
\hline & $\begin{array}{l}\text { Correlation } \\
\text { Coefficient }\end{array}$ & $\begin{array}{c}\text { Partial Regression } \\
\text { Coefficient }\end{array}$ & $\begin{array}{c}\text { Standard Partial Regression } \\
\text { Coefficient }\end{array}$ & $\mathbf{t}$ & Sig. & \\
\hline Constant & - & 1.939 & - & 18.776 & .000 & - \\
\hline Knowing the customers & .660 & .220 & .369 & 7.379 & .000 & 2 \\
\hline Knowing the competitors & .705 & .272 & .483 & 9.655 & .000 & 1 \\
\hline \multicolumn{7}{|c|}{$\mathrm{F}$ value $=183.263 \mathrm{Sig}=0.000$ Determination coefficient $=0.584$ error $=0.645$} \\
\hline
\end{tabular}

From the foregoing, it is clear that first hypothesis is true:

"There is a relationship and statistically significant impact between market knowledge dimensions and the Blue Ocean Strategy dimensions (at the macro level), and between each dimension of market knowledge dimensions (at the micro level) and the Blue Ocean Strategy dimensions (at the macro level)."

The second hypothesis:

"There is a relationship and a statistically significant impact between the Blue Ocean Strategy dimensions and the competitive advantage dimensions (at the macro level), and between every dimension of the Blue Ocean strategy at the micro level) and the competitive advantage dimensions (at the macro level)."

To test this hypothesis, we used Pearson correlation coefficient between the Blue Ocean Strategy and its various dimensions and the competitive advantage and its various dimensions, and partial regression as follows:

\section{Correlation Coefficients}

Table (6) displays correlation coefficients between the Blue Ocean strategy and its dimensions and the competitive advantage and its dimensions. The table shows high correlation coefficient between the overall average of the views of the study sample about the Blue Ocean Strategy (as a whole) and the competitive advantage (as a whole) where the value of the correlation coefficient is $(0.711)$. This means that there is a strong proportional (positive) correlation between the Blue Ocean Strategy (as a whole) and competitive advantage (as a whole), and it is significant at the significance level of $1 \%$. There is a strong proportional correlation between innovation as one of the dimensions of the Blue Ocean Strategy and the competitive advantage (as a whole) where the value of the correlation coefficient is
(0.672), i.e., there is a strong proportional (positive) correlation between the two variables, and it is significant at the significance level of $1 \%$. There is also a strong proportional correlation between the increase as one of the Blue Ocean Strategy dimensions and the competitive advantage (as a whole) where the value of the correlation coefficient is $(0.607)$, i.e., there is a strong proportional (positive) correlation between the two variables, and it is significant at the significance level of $1 \%$. There is also a moderate proportional correlation between the exclusion as one of the dimensions of the Blue Ocean Strategy and the competitive advantage (as a whole) where the value of the correlation coefficient is $(0.411)$, i.e., there is a moderate proportional positive correlation between the two variables. There is also a moderate proportional correlation between the reduction as one of the dimensions of the Blue Ocean Strategy and the competitive advantage (as a whole) where the value of the correlation coefficient is $(0.401)$, i.e., there is a moderate proportional positive correlation between the two variables.

With regard to the relationship between the dimensions of the Blue Ocean Strategy and the dimensions of competitive advantage (at the micro level), it is noted from Table (6) that there is a strong proportional (positive) correlation between the increase dimension as one of the dimensions of the Blue Ocean Strategy and the quality dimension as one of the dimensions of the competitive advantage where the value of the correlation coefficient is $(0.607)$, and it is significant at the significance level of $1 \%$. The lowest value of the correlation coefficient was between the reduction dimension as one of the dimensions of the Blue Ocean Strategy and the delivery as one of the dimensions of competitive advantage, where the value of the correlation coefficient is $(0.175)$, i.e. there is a weak proportional correlation between the two dimensions and it is significant at the significance level of $1 \%$. 
Table 6. Correlation coefficients between the Blue Ocean Strategy dimensions and competitive advantage dimensions

\begin{tabular}{|c|c|c|c|c|c|}
\hline & $\begin{array}{c}\text { Blue Ocean Strategy } \\
\text { as a whole }\end{array}$ & $\begin{array}{c}\text { Elimination } \\
\text { dimension }\end{array}$ & $\begin{array}{c}\text { Reduction } \\
\text { dimension }\end{array}$ & $\begin{array}{c}\text { Increasing } \\
\text { dimension }\end{array}$ & Creativity dimension \\
\hline Competitive advantage as a whole & $.711^{* *}$ & $.411^{* *}$ & $.401^{* *}$ & $.607^{* *}$ & $.672^{* *}$ \\
\hline Cost dimension & $.482^{* *}$ & $.350^{* *}$ & $.304^{* *}$ & $.362^{* *}$ & $.454^{* *}$ \\
\hline Quality dimension & $.597^{* *}$ & $.345^{* *}$ & $.302^{* *}$ & $.607^{* *}$ & $.544^{* *}$ \\
\hline Flexibility dimension & $.397^{* *}$ & $.223^{* *}$ & $.233^{* *}$ & $.299^{* *}$ & $.456^{* *}$ \\
\hline Delivery dimension & $.511^{* *}$ & $.271^{* *}$ & $.175^{* *}$ & $.537^{* *}$ & $.553^{* *}$ \\
\hline Innovation dimension & $.526^{* *}$ & $.382^{* *}$ & $.190^{* *}$ & $.446^{* *}$ & $.582^{* *}$ \\
\hline
\end{tabular}

** Significant coefficients at the significance level of $1 \%$

\section{Partial Regression}

Table (7) displays partial regression model estimates for the dependent variable (competitive advantage) on the independent variables (the Blue Ocean Strategy dimensions). The table clearly shows the significance of the estimated regression model at the significance level of 0.01 where the calculated $(\mathrm{F})$ test value is $(88.992)$ and Sig $(\mathrm{P}-$ value $=0.000)$ lower than the level of significance. The table clearly shows the partial regression coefficients (path coefficients) for the dimensions of the Blue Ocean Strategy and the constant value through the t value and Sig (P-value). The most important Blue Ocean Strategy dimensions that affect the competitive advantage as a whole according to the standard partial regression coefficient in the model are:
- Creativity
- Increasing
- Elimination
- Reduction

The value of the coefficient of determination is (0.579) which shows that the Blue Ocean dimensions as independent variables explain $57.9 \%$ of the changes in the dependent variable (competitive advantage as a whole). Table (7) clearly shows that all the signs of the partial regression coefficients are positive, which indicates that there is a proportional relationship between the independent variables (the dimensions of the Blue Ocean Strategy) and the dependent variable (competitive advantage as a whole).

Table 7. Partial regression model estimates

\begin{tabular}{|c|c|c|c|c|c|c|}
\hline \multirow{2}{*}{ Independent variables } & \multicolumn{5}{|c|}{ Estimates } \\
\cline { 2 - 7 } & $\begin{array}{c}\text { Correlation } \\
\text { Coefficient }\end{array}$ & $\begin{array}{c}\text { Partial Regression } \\
\text { Coefficient }\end{array}$ & $\begin{array}{c}\text { Standard Partial } \\
\text { Regression Coefficient }\end{array}$ & t & Sig. & Order \\
\hline Constant & - & .919 & - & 5.188 & .000 & - \\
\hline Elimination & .411 & .189 & .210 & 5.188 & .000 & 3 \\
\hline Reduction & .313 & .153 & .171 & 3.775 & .000 & 4 \\
\hline Increasing & .587 & .203 & .228 & 5.283 & .000 & 2 \\
\hline Creativity & .672 & .401 & .432 & 11.207 & .000 & 1 \\
\hline & \multicolumn{7}{|c|}{ F value $=88.992$ sig=0.000 determination coefficient=0.579 error $=0.649$} & & \\
\hline
\end{tabular}

From the foregoing, it is clear that the second hypothesis is true:

"There is a relationship and a statistically
significant impact between the Blue Ocean
Strategy dimensions and the competitive
advantage dimensions (at the macro level), and
between every dimension of the Blue Ocean
strategy at the micro level) and the competitive
advantage dimensions (at the macro level)."

The third hypothesis:
"There is a relationship and statistically significant impact between market knowledge dimensions and competitive advantage dimensions (at the macro level), and between each dimension of market knowledge dimensions (at the micro level) and the dimensions of competitive advantage (at the macro level)."

To test this hypothesis, we used Pearson correlation coefficient between market knowledge and its two dimensions and competitive advantage and its dimensions, and partial regression as follows: 


\section{Correlation Coefficients}

Table (8) displays correlation coefficients between market knowledge and its two dimensions and competitive advantage and its dimensions. The table clearly shows the high correlation coefficient between the overall average for the study participants views about market knowledge and competitive advantage as a whole, where the value of the correlation coefficient is (0.752), i.e. there is a strong proportional (positive) correlation between market knowledge (as a whole) and competitive advantage (as a whole), and it is significant at the significance level of $1 \%$. There is a strong proportional correlation between knowing the competitors as one of the dimensions of market knowledge and the total degree of competitive advantage, where the value of the correlation coefficient is $(0.692)$, i.e., there is a strong proportional (positive) correlation between knowing competitors as one of the dimensions of market knowledge and competitive advantage as a whole, and it is significant at significance level of $1 \%$. Moreover, There is a strong proportional correlation between knowing the customers as one of the dimensions of market knowledge and the total degree of competitive advantage, where the value of the correlation coefficient is $(0.653)$, i.e., there is a strong proportional (positive) correlation between knowing the customers as one of the dimensions of market knowledge and the competitive advantage as a whole, and it is significant at the significance level of $1 \%$.

With regard to the relationship between market knowledge dimensions and competitive advantage dimensions (at the micro level), it is noted from table (8) that there is a strong proportional (positive) correlation between knowing the competitors dimension as one of the dimensions of market knowledge and the innovation dimension as one of the dimensions of competitive advantage, where the value of the correlation coefficient is $(0.630)$, and it is significant at the significance level of $1 \%$. The lowest value of the correlation coefficient was between knowing the customers dimension as one of the dimensions of market knowledge and the cost dimension as one of the dimensions of competitive advantage, where the value of the correlation coefficient is $(0.354)$, i.e. there is a weak proportional correlation between the two dimensions and it is significant at the significance level of $1 \%$.
Table 8. Correlation coefficients between market knowledge and competitive advantage and its dimensions

\begin{tabular}{|c|c|c|c|}
\hline & $\begin{array}{c}\text { Market } \\
\text { knowledge }\end{array}$ & $\begin{array}{c}\text { Knowing the } \\
\text { customers }\end{array}$ & $\begin{array}{c}\text { Knowing the } \\
\text { competitors }\end{array}$ \\
\hline $\begin{array}{c}\text { Competitive } \\
\text { advantage }\end{array}$ & $.752^{* *}$ & $.653^{* *}$ & $.692^{* *}$ \\
\hline Cost & $.420^{* *}$ & $.354^{* *}$ & $.398^{* *}$ \\
\hline Quality & $.666^{* *}$ & $.580^{* *}$ & $.611^{* *}$ \\
\hline Flexibility & $.502^{* *}$ & $.429^{* *}$ & $.468^{* *}$ \\
\hline Delivery & $.644^{* *}$ & $.603^{* *}$ & $.551^{* *}$ \\
\hline Innovation & $.660^{* *}$ & $.550^{* *}$ & $.630^{* *}$ \\
\hline
\end{tabular}

** Significant coefficients at the significance level of $1 \%$

\section{Partial Regression}

Table (9) displays partial regression model estimates of the dependent variable (competitive advantage as a whole) on the independent variables (market knowledge dimensions). The table clearly shows the significance of the estimated regression model at the significance level of 0.01 , where the calculated (F) test value is (170.593) and Sig (Pvalue $=0.000$ ) lower than the level of significance. The table clearly shows the significance of partial regression coefficients (path coefficients) (knowing the customers market and knowing the competitors) and the constant value through the $t$ value and Sig (P-value). Market knowledge dimensions that affect competitive advantage as a whole according to the standard partial regression coefficient in the model are:

\section{- Knowing the competitors \\ - Knowing the customers}

The value of the coefficient of determination is $(0.567)$ which shows that the dimensions of market knowledge as the independent variables explain $56.7 \%$ of the changes in the dependent variable (competitive advantage as a whole).

Table 9 clearly shows that all partial regression coefficients have positive signs which shows a proportional relationship between the independent variables (the dimensions of market knowledge) and the dependent variable (competitive advantage as a whole)

Table 9. Partial regression model estimates

\begin{tabular}{|c|c|c|c|c|c|c|}
\hline \multirow{2}{*}{ Independent variables } & \multicolumn{5}{|c|}{ Estimates } & \multirow{2}{*}{ Order } \\
\hline & $\begin{array}{l}\text { Correlation } \\
\text { Coefficient }\end{array}$ & $\begin{array}{c}\text { Partial Regression } \\
\text { Coefficient }\end{array}$ & $\begin{array}{c}\text { Standard Partial } \\
\text { Regression Coefficient }\end{array}$ & $\mathbf{t}$ & Sig. & \\
\hline Constant & - & 1.759 & - & 15.457 & .000 & - \\
\hline Knowing the customers & .653 & .238 & .370 & 7.252 & .000 & 2 \\
\hline Knowing the competitors & .692 & .285 & .469 & 9.190 & .000 & 1 \\
\hline \multicolumn{7}{|c|}{$F$ value $=170.593 \mathrm{sig}=0.000$ determination coefficient $=0.567$ error $=0.658$} \\
\hline
\end{tabular}


From the foregoing, it is clear that the third hypothesis is true:

"There is a relationship and statistically significant impact between market knowledge dimensions and competitive advantage dimensions (at the macro level), and between each dimension of market knowledge dimensions (at the micro level) and the dimensions of competitive advantage (at the macro level)."

Fourth hypothesis:

"There is a direct and a statistically significant impact of market knowledge on achieving competitive advantage through the Blue Ocean Strategy"

Table (10) and Figure (2) show estimates of the partial regression model for the dependent variable (competitive advantage as a whole) on the independent variables (market knowledge dimensions and Blue Ocean Strategy as a whole). The table clearly shows the significance of the estimated regression model at the significance level of 0.01 , where the calculated (F)test value is (209.697) and Sig (P-value =
0.000) lower than the level of significance. The table clearly shows the significance of partial regression coefficients (path coefficients) (knowing the customers and knowing the competitors and the Blue Ocean Strategy as a whole) and the constant value through the $t$ value and Sig ( $\mathrm{P}$ - value). The most important independent variables that affect the competitive advantage as a whole according to the standard partial regression coefficient in the model are:

- The Blue Ocean Strategy as a whole

- Knowing the competitors

- Knowing the customer market

The value of the coefficient of determination is (0.708) which shows that the dimensions of market knowledge and the Blue Ocean Strategy (as a whole) as independent variables explain $70.8 \%$ of the changes in the dependent variable (competitive advantage as a whole).

Signs of the partial regression coefficients are positive, which indicate that there is a positive relationship between the independent variables (dimensions of market knowledge and the Blue Ocean Strategy as a whole) and the dependent variable (competitive advantage as a whole).

Table 10. Partial regression model estimates

\begin{tabular}{|c|c|c|c|c|c|c|}
\hline \multirow[b]{2}{*}{ Independent variables } & \multicolumn{5}{|c|}{ Estimates } & \multirow[b]{2}{*}{ Order } \\
\hline & $\begin{array}{l}\text { Correlation } \\
\text { Coefficient }\end{array}$ & $\begin{array}{c}\text { Partial Regression } \\
\text { Coefficient }\end{array}$ & $\begin{array}{c}\text { Standard Partial } \\
\text { Regression Coefficient }\end{array}$ & $\mathbf{t}$ & Sig. & \\
\hline Constant & - & .505 & - & 3.125 & .002 & - \\
\hline Knowing the customers & .653 & .152 & .210 & 4.549 & .000 & 3 \\
\hline Knowing the competitors & .692 & .244 & .356 & 7.281 & .000 & 2 \\
\hline Blue Ocean Strategy as a whole & .711 & .466 & .383 & 7.374 & .000 & 1 \\
\hline
\end{tabular}

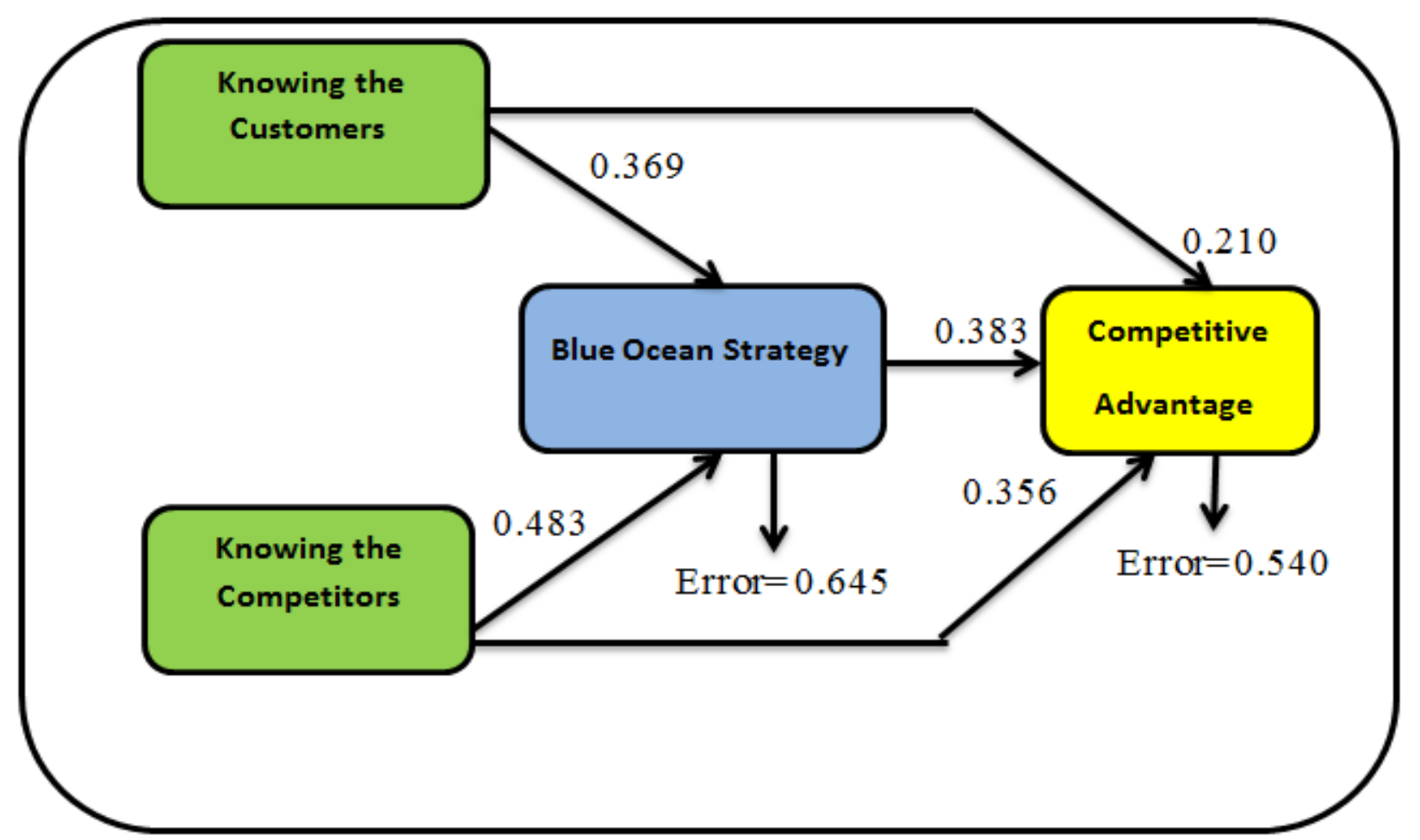

Figure 2. Results of the fourth hypothesis of the path analysis model 
Through testing the first hypothesis results, it was found that the value of the coefficient of determination of the Blue Ocean Strategy regression as a whole on the market knowledge dimensions is $(0.584)$. And by mediating the Blue Ocean Strategy as a whole between the market knowledge dimensions and competitive advantage, it was found that the value of the coefficient of determination $(0.708)$ is high, i.e. the explanatory power of market knowledge dimensions has increased when centralizing the Blue Ocean Strategy as a whole, where the value of the coefficient of determination of regression of competitive advantage as a whole on the market knowledge is $(0.567)$ from the third hypothesis. This confirms the low value of the error until it reached $(0.540)$ in the case of centralizing the Blue Ocean Strategy as a whole between the dimensions of market knowledge and competitive advantage.

Figure (2) shows that there is a direct impact between market knowledge dimensions and competitive advantage, and that there is an indirect effect through the impact of market knowledge dimensions on the Blue Ocean Strategy and the impact of the Blue Ocean Strategy on competitive advantage. From the foregoing, it is clear that the fourth hypothesis is true:

"There is a direct and a statistically significant impact of market knowledge on achieving competitive advantage through the Blue Ocean Strategy"

\section{Results}

This study aimed to find out the awareness degree of staff who occupy supervisory positions in Marketing Management at STC of the reality of market knowledge and the philosophy of the Blue Ocean Company, and their role in improving and strengthening competitive advantage. It also aimed to identify the nature of the relationship and impact between market knowledge dimensions (at the macro level) and the Blue Ocean Strategy dimensions (at the macro level), and between each dimension of market knowledge dimensions (at the micro level) and the Blue Ocean Strategy dimensions (at the macro level). The study also aimed to identify the nature of the relationship and impact between the Blue Ocean Strategy dimensions (at the macro level) and the competitive advantage dimensions (at the macro level), and between each dimension of the Blue Ocean Strategy dimensions (at the micro level) and the competitive advantage dimensions (at the macro level). In addition to that, it tried to identify the nature of the relationship and impact between market knowledge dimensions (at the macro level) and the competitive advantage dimensions (at the macro level), and between each dimension of market knowledge dimensions (at the micro level) and the competitive advantage dimensions (at the macro level). Moreover, it tried to identify the nature of the relationship and the indirect impact of market knowledge to achieve competitive advantage through the Blue Ocean Strategy. Based on the previous statistical analysis, the following results can be presented:

1. The results of the study indicate that there is a high impression among study participants about market knowledge dimensions, where the arithmetic mean value is equal to (3.81). Accordingly, the Results of this study are consistent with results of previous studies, for example, [1]; [13].

2. The results also indicate that there is a high impression among study participants about the Blue Ocean Strategy, where the arithmetic mean value is equal to (3.83). This also confirms that the results of this study are consistent with results of previous studies, for example, [32]; [2].

3. Likewise, the results of this study indicate that there is a high impression among study participants about competitive advantage, where the arithmetic mean value is equal to (3.81).Her again, the results of this study were found to be consistent with results of previous studies, for example, [32]; [14]; [2].

4. Results of this study indicate that there is a proportional strong (positive) relationship between market knowledge dimensions and the Blue Ocean Strategy dimensions (at the macro level), and between knowing the customers and knowing the competitors dimensions (market knowledge dimensions at the micro level) and the Blue Ocean Strategy dimensions (at the macro level). It is significant at the significance level is $1 \%$. There is a statistically significant impact for market knowledge dimensions on the Blue Ocean Strategy, where knowing the competitors and knowing the customers dimensions (respectively) affect the dependent variable (the Blue Ocean Strategy), so these variables explain $58.4 \%$ of the changes that occur in the dependent variable (the Blue Ocean Strategy). Some previous studies suggested that market knowledge (knowing customers and competitors) play a large role in determining the competitive strategic choice [13]; [10].

5. furthermore, the results of this study indicate the presence of a strong proportional(positive) correlation between the Blue Ocean Strategy dimensions and the competitive advantage dimensions (at the macro level), and it is significant at the significance level of $1 \%$. There is also a strong proportional (positive) correlation between the innovation dimension and the increase dimension (of the Blue Ocean Strategy dimensions) and competitive advantage dimensions (at the macro level). It is significant at the significance level of $1 \%$. There is also a moderate proportional (positive) correlation between the exclusion dimension and the reduction dimension (of the Blue Ocean Strategy dimensions) and competitive advantage dimensions (at the macro level). It is significant at the significance level of $1 \%$. There is also a statistically significant impact of the Blue Ocean Strategy on the competitive advantage, which the dimensions of innovation, increase, exclusion and reduction (respectively) affect the dependent variable (competitive advantage), where these variables explain $57.9 \%$ of the changes that occur in the dependent variable (competitive advantage). Results of this study are consistent 
with the results of some previous studies such as [32]; [14]; [2]; [16].

7. The results also indicate the presence of a strong proportional relationship between market knowledge dimensions (at the macro level) and competitive advantage (at the macro level), and it is significant at the significance level of $1 \%$, and between knowing the customers and knowing the competitors dimensions (at the micro level) and competitive advantage dimensions (at the macro level). It is significant at the significance level of $1 \%$. There is a statistically significant impact of market knowledge dimension on the competitive advantage, where knowing the competitors and knowing the customers (respectively) affect the dependent variable (competitive advantage), where these variables explain $72.3 \%$ of the changes that occur in the dependent variable (the competitive advantage). The results of this study are consistent with the results of some previous studies such as [30]; [16]; [17]; [18].

8. In addition to the above, the results of this study indicate the existence of a direct impact of market knowledge dimensions and competitive advantage, and that there is an indirect impact through the impact of market knowledge on the Blue Ocean Strategy dimensions and the impact of the Blue Ocean Strategy on competitive advantage.

\section{Recommendations}

In the light of the above results, it was possible to reach some scientific recommendations that include the following:

1. The results indicate that market knowledge dimensions (knowing the competitors and knowing the customers) (respectively) have an impact on the Blue Ocean Strategy and competitive advantage, so the management of the company under study must do the following:

- It must establish an administrative unit that organizes knowledge management efforts in the company under study, and it must be independent and linked to senior management, or it must be attached to the management of Research and Development. Work must be performed to create databases where all collected information about the different aspects of performance in the company under study is saved.

- The senior management in the company under research must recognize that market knowledge (knowing the customers and knowing the competitors) play a big role in the selection of the appropriate marketing strategy. Achieving competitive advantage also requires the managers and heads of departments in the company under study to pay more attention to market knowledge and to promote and transfer it and to keep up with the continuously changing market environment, and provide marketing programs to meet the constantly changing needs and desires of customers and outperform competitors.

- It must adopt market knowledge as an input to develop and improve individual and organizational performance of the company under study, as this will bring the company many benefits including: increasing its capacity to adapt to the changes happening in the surroundings, increasing its capacity to meet the needs of the society in addition to increasing its capacity for creativity and innovation.

2. The results indicate that the Blue Ocean Strategy dimensions: - creativity, increasing, elimination and reduction (respectively) affect competitive advantage, so the management of the company under study must do the following:

- Adopt a policy to provide new ideas and services, in line with society's needs and desires, and encourage their employees to offer new ideas, providing them with full freedom in participating with the senior management to introduce new and innovative ideas, as well as giving them financial and moral rewards for each new idea that serves the company.

- It must focus on the increasing strategy by increasing their distribution outlets specialized in contacting the user to increase the market share and increase the quality of service provided which increases the confidence of the user in the company.

- It must focus on the reduction strategy, by reducing non-essential services, getting rid of ideas that can hardly be executed, and of useless weak and poor quality services, reducing unnecessary expenses, stopping the ideas even if they are economically and technically good and reducing waste and loss in service production requirements and time allocated to deliverables.

- It must focus on the elimination strategy, by the eliminating materials and procedures that are not necessary, without compromising the quality of service and the size of their sales, reducing marketing costs to a minimum through getting rid of inefficient staff who hinder their competitive superiority and excluding everything that is not necessary for the process of service production to raise the efficiency and effectiveness of the service provided.

3. The management of the company under study must recognize that the achievement of competitive advantage does not mean superiority in all the elements, but rather to focus on one or more of these elements because of the nature of the competition prevailing in the market.

4. There is a need to pay more attention to marketing representatives in the company under study by continuing training on policy development to give them the skills, competencies and expertise necessary to accomplish their work with all efficiency and professionalism.

5. Saudi organizations in general and service organizations in particular must adopt creative ideas to confront the prevailing state of atrophy resulting from the opening up of the local market, and the existence of alternatives for their products. The Blue Ocean Strategy is 
perhaps one of those creative ideas that have proven successful in many international organizations.

\section{REFERENCES}

[1] Khelfaoui, Hakeem (2015) The Role of Market Knowledge to Achieve Marketing Innovation in a Prospective Study at a Number of Food Industry Companies in Algeria, the New Economy Journal, Vol. 1, No. 12, pp. 173-193.

[2] Al-Tai, Joseph (2006) Blue Market Strategy and its role in Achieving Competitive edge: An Empirical Study in Kufa Pepsi plant, Qadisiyah Journal for Administrative and Economic Sciences, Koufa University, Vol. 8, No. 4, pp. $8-52$

[3] Rauf, Raad (2010) The Role of Blue Ocean Strategy Dimensions in Marketing Performance Application to Public Companies for the Manufacture of Medicines and Medical Supplies Nienawah, Iraq ,alrafedain journal, Vol. 32, No. 98, pp. 317-335.

[4] Kim, W. C., and Mauborgne, R. (2005) Blue Ocean Strategy. Boston: Harvard Business School Publishing Corporation.

[5] Rawabdeh, et al. (2012) Blue Ocean Strategy as a Tool for Improving a Company's Marketing Function: The case of Jordan, Jordan Journal of Business Administration, Vol. 8, No. 2, pp. 290-406.

[6] Madden, R. (2009) Philosophical Approach to Economic Recovery. Marketing Week. Vol. 32, pp.15-16.

[7] Leavy, B. (2005) Value Pioneering-How to Discover Your Own "Blue Ocean": Interview with W. Chan Kim and Renée Mauborgne. Strategy and Leadership. Vol. 33, pp. 13-20.

[8] Sheehan, N.T. Vaidyanathan, G. (2009) Using a Value Creation Compass to Discover "Blue Oceans". Strategy and Leadership, Vol. 37, No 2, pp. 13-20.

[9] Sushil (2006) Flowing Stream Strategy and Blue Ocean Strategy. Global Journal of Flexible Systems Management, Vol. 7, No. 3/4. Piii.

[10] Jawad, Adnan (2003) The impact of Market Knowledge in Selection of Competitive Strategies and Excellence in Performance (a Prospective Study in the Durable Goods Sector in the Jordanian Market), Jordan Journal of Applied Sciences, Vol. 6, No. 2, pp. 24-46.

[11] Blythe, Jim.(2003) Marketing Strategy, McGraw Hill.

[12] Idriss, thabit \& Ghais, Mona (1994) Marketing Management, an Applied Strategic Approach, Alfalah Library for Publication and Distribution, Kuwait.

[13] Dahbour, Luay (2010) The Role of Market Knowledge in Competitive Strategies Selection, for a Sample of the Jordanian Private Higher Education Institutions, Master thesis, Business Administration, Middle East University.

[14] Al-Attar, Fouad (2010) The Role of Blue Ocean Philosophy of Achieving Competitive Excellence, Exploratory Study for Views of a Sample Workers in Zain Telecom in Baghdad, Karbala University Scientific Journal, No. 3, pp. 52-68

[15] Albanaa, Zeinab (2009) The Role of Blue Ocean Strategy to
Achieve Sustainable Competitive Advantage: Comparative Study to a Sample of Zain and Asia Sail Telecom, Master Thesis, Faculty of Business and Economics, Karbala University.

[16] Meihami1, B. and Meihami, H. (2014) Knowledge Management a Way to Gain a Competitive Advantage in Firms (Evidence of Manufacturing Companies, International Letters of Social and Humanistic Sciences Vol. 14, pp. 80-91.

[17] Dehkordi, G. J. Rezvani, S \& Behravan R (2012) Blue Ocean Strategy: A Study over a Strategy Which Help the Firm to Survive From Competitive Environment, International Journal of Academic Research in Business and Social Sciences Vol.2, No. 6, pp. 477- 482.

[18] Kamya, M. T. , Ntayi, J. M. and Ahiauzu, A. (2010) Knowledge Management and Competitive Advantage: The Interaction Effect of Market Orientation, African Journal of Business Management Vol. 4, No. 14, pp. 2971-2980.

[19] Chen Mu-Yen, \& Chen An-Pin (2006) Knowledge Management Performance Evaluation: a Decade Review From 1995-2004. J. Inf. Sci., Vol.32, No.1, PP. 17-38.

[20] Al-Bustnji, Ghalib (2014) The Impact of Using Marketing Mix Service with Islamic Character to Build a Competitive Advantage in Saudi Telecom Company STC, Journal of Imam Muhammad bin Saud Islamic University, Faculty of Humanities and Social Sciences, No. 31, pp. 134-191.

[21] Abu Fara, Joseph (2004) The Relationship Between Using of Knowledge Management and Performance an Applied Strategic Approach, the Fourth Annual International Conference, Zaytuna University, Jordan.

[22] Abdel-Fattah, Mohammed (2011) Strategic Marketing, the Arab Bureau of Knowledge, Cairo, Egypt.

[23] Almograbi, Abdel-Hamid (2009) Strategic Management, Measuring the Balanced Performance, Modern Library, Egypt.

[24] AlBakri, Thamer (2010) Marketing Researches: Principles and Cases, the First Edition, Dar Ethraa for Publication and Distribution, Amman.

[25] Alhayali, S, Sltan, M., Barjes M. A., and Aboud N. A., (2013) Reflection Electronic Authentication in Achieving Competitive Advantage, Prospective Study for Human Resources Groups in a Sample of Faculties of Mosul University, the Nineteenth Conference of the Association Special Libraries - Arabian Gulf Chapter: future of the profession : Breaking traditional barriers to library and information profession and the shift towards digital future professional environment - the United Arab Emirates, pp. 624-658.

[26] Ibrahim Bushra, (2006) The Impact of Preferences Quality Dimensions on Iraqi Consumer, Master Thesis, College of Technology, Baghdad, Iraq.

[27] Alali, Abdul Sattar (2006) Production and Operations Management "Quantitative Approach", Second Edition, Dar Wael for publication, Amman.

[28] Altaweel, Akram and Ismail, Ragheed (2008) the Relationship Between Types of Technical Innovation and the Dimensions of Competitive Advantage: a Field Study in a Select Group of Industrial Firms in the Province of Nienawah, 
Faculty of Management and Economics, Industrial Management Department, Mosul University, Iraq.

[29] Alsaati, Afaf (2000) Recommending Broad System and Prospects for its Application in Iraqi industry: an Exploratory Study for a Sample of the Views of Iraqi Managers at Industrial Companies, Ph.D., Faculty of Management and Economics, Baghdad University.

[30] Shubaki, Arkan and Hani Al-Jabi (2011) The Role of Knowledge Management in Achieving Competitive Advantage at Insurance Companies Operating in Nables city, Research for a Bachelor's Degree, An-Najah National University, Faculty of Economics and Administrative Sciences, Department of Business Administration, Nables.

[31] Al-Alawi A, Al-Marzooqi N, and Mohammed Y., (2007) Organizational Culture and Knowledge Sharing: Critical Success Factors, J. Knowl. Manage, Vol. 11, No. 2, pp. 22-42.

[32] Adila, Dreams (2014) The Role of the Blue Ocean Strategy to Achieve Sustainable Competitive Advantage Status of Algiers Biskra Communication Foundation Study, Master Thesis, Faculty of Economic and Commercial Sciences Altser, Department of Management Science, University of Mohamed Khider, Biskra, Algeria.

[33] Becker, H. (2013) Imax Move to Hollywood: Blue Ocean Strategy or a Case of Who Moved My Cheese, Global Conference on Business and Finance Proceedings, Vol. 8, No. 2, pp. 472-476. Chaoren, L. and Thawatthatree, A. (2011) Use Value Innovation to Create Competitive Advantages in Blue Ocean: A Case Study of IKEA in Nanjing, Karlstads Business School, Karlstads University.

[34] Cirjevskis, A., Homenko, G., and Lacinova, V., (2011) How to Implement Blue Ocean Strategy (BOS) in B2B Sector, Business, Management and Education, Vol. 9, No, 2, pp. 201-215. [35] Trombetta, R G, (2008) Design Your Future: Blue Ocean Strategy [J]. DMI News \& Views, No. 1, pp7-12. From http://www. dmi.org/dmi/html.

[35] Trombetta, R G, (2008) Design Your Future: Blue Ocean Strategy [J]. DMI News \& Views, No. 1, pp7-12. From http://www. dmi.org/dmi/html.

[36] Zhao, W. and Jinwei, Y (2010) Application of Blue Ocean Strategy to Chinese 3G Mobile Telecom Industry, Thesis of Master of Science in Business

Administration ,From,http://www.bth.se/fou/cuppsats.nsf/all/ b378ba60a5008ec5c125783b00499608/\$file/thesis2010-061 0\%20wang\%20och\%20yang.pdf.

[37] Pitta, D. (2009) Issues in a Down Economy: Blue Oceans and New Product Development, Journal of Product \& Brand Management, Vol. 18, No. 4, pp. 292-296.

[38] Butler, C. (2008) Planning with Blue Ocean Strategy in the United Arab Emirates, Strategic Change, Vol. 17, pp. 169-178.

[39] Kima, C., Yang, K. H. \& Kim, J. (2007) A Strategy for Third-Party Logistics Systems. The International Journal of Management Science, Vol. 36, pp. 522-534.

[40] Obidat, T, lentils, A., and Abdul Haq, K. (2006) Scientific Research, Concept, Tools, Methods, 3rd Floor, Dar Osama for Publishing and Distribution, Riyadh.

[41] Nunnally J. C., and Bernstein, I H., (1994) Psychometric Theory, 3rd Ed., (London: McGraw-Hill). 